\title{
Review \\ Developments in the scientific and clinical understanding of fibromyalgia
}

\author{
Dan Buskila
}

Division of Internal Medicine, Department of Medicine H, Soroka Medical Center, Faculty of Health Sciences, Ben Gurion University, P.O.B. 151, Beer Sheva 84101, Israel

Corresponding author: Dan Buskila, dbuskila@bgu.ac.il

Published: 14 October 2009

This article is online at http://arthritis-research.com/content/11/5/242

(C) 2009 BioMed Central Ltd
Arthritis Research \& Therapy 2009, 11:242 (doi:10.1186/ar2720)

pain processing characteristic of $\mathrm{FM}$, and this evolution of knowledge is leading towards novel strategies for management of FM pain [3]. Increasing evidence supports a genetic predisposition to $\mathrm{FM}$ and supports the fact that environmental factors may trigger the development of FM, in genetically predisposed individuals [4-6]. There is also a continued effort to search for biomarkers to be used to identify individuals susceptible to FM, for the diagnosis of FM and for objective measures of disease activity [7].

An effort has also been made to better classify FM patients, to identify subgroups with unique clinical characteristics and to pinpoint therapeutic interventions. The recent Food and Drugs Administration approval of pregabalin, duloxetine and milnacipran as specific medications for FM may herald a new era for the development of medications with higher specificity and efficacy for this condition. The aim of the present article is to review the current developments in the scientific and clinical understanding of FM and progress in the management of FM.

\section{Classification and diagnostic criteria}

ACR criteria define FM as a chronic disorder characterized by the presence of widespread pain accompanied by tenderness upon palpation of at least 11 out of 18 predefined tender points throughout the musculoskeletal system [1]. The 1990 ACR classification criteria for FM were developed initially to facilitate research by identifying homogeneous groups so that results from different studies could be interpreted. In actual clinical practice it is currently common knowledge that there is nothing particularly sacred about the number 11. Using the ACR criteria in diagnosis of FM raises a number of problems. Tender points and widespread pain alone do not capture the essence of FM, multiple symptoms of which prominently include fatigue, sleep disturbance and cognitive dysfunction [8].
Significant progress has occurred over recent years regarding our understanding of the mechanisms underlying altered 
The concept of using tender points as the defining feature of FM has also drawn criticism [9]. The tender points have been criticized due to the arbitrary nature of the 11-point cutoff, due to the lack of a clear association between tender points and the underlying pathophysiology of FM, and due to the close association between tender points and distress, which has led to the characterization of tender points as a sedimentation rate of distress [10]. Clauw and Crofford have pointed out that, in contrast to women being 1.5 times as likely to experience chronic widespread pain, they are about 10 times as likely to meet the criteria for FM [11]. It was suggested that this disparity between the gender differential for chronic widespread pain and FM is due solely to the ACR criteria requiring 11 out of 18 tender points - this finding occurs 11 times more commonly in women than in men [11]. Wolfe developed an instrument that he designated a regional pain scale, which assessed various articular and nonarticular body regions for pain [12]. When combined with other assessments, such as a fatigue visual analog scale, the regional pain scale correctly identified most patients diagnosed as having FM by their rheumatologists [12].

Despite all of the critiques on the ACR criteria, these criteria served us well by enhancing much of the research in the field of FM. In the future, revised or newer classification criteria should be established, incorporating the large body of scientific data that have been gathered in the past decade.

\section{Subtypes of fibromyalgia}

Over the years it has became clear that FM is not a homogeneous condition. Although chronic widespread pain and increased tenderness are universally present, other associated symptoms are not present in all patients. Turk and coworkers showed that the subgroups identified by cluster analyses of the Multidimensional Pain Inventory in various chronic pain populations may also apply to a population of FM patients, and that each of the FM subgroups responds differently to treatment $[13,14]$. They analyzed data from three empirically based subgroups of dysfunctional, interpersonally distressed or adaptive coppers, all of whom underwent a standardized treatment program, and concluded that customizing treatment on the basis of psychosocial needs is likely to enhance treatment efficacy. Thieme and coworkers classified FM patients as dysfunctional, interpersonally distressed or adaptive coppers based on their responses to the Multidimensional Pain Inventory, and used hierarchical regression analyses to identify the predictors of pain behaviors for the population as a whole, and for the subgroups [15].

These results indicated that different variables account for the presence of pain behaviors in different subgroups of patients. It was concluded that the data provide support for the heterogeneity of the diagnosis of FM and have implications for treatment of subgroups of patients [15].
A study by Giesecke and colleagues using cluster analysis suggested that there may be three different subtypes of FM [16]. There appeared to be a group of FM patients who exhibit extreme tenderness but lack any associated psychological/cognitive factors, an intermediate group who display moderate tenderness and have normal mood, and a group in whom mood and cognitive factors may be significantly influencing the symptom report. Recent evidence suggests a role for polymorphisms of genes in the serotoninergic, dopaminergic and catecholaminergic systems in the pathogenesis of FM [4-6]. The knowledge of these gene polymorphisms may help with better subgrouping of FM patients in the future and may help in designing a more specific pharmacologic treatment approach.

\section{Fibromyalgia - a member of the functional somatic syndromes}

Functional somatic syndromes (FSS) are defined as a group of related syndromes characterized more by symptoms, suffering and disability than by structural or functional abnormality [17]. It is now known that FM overlaps and is associated with a variety of other FSS, including chronic fatigue syndrome, irritable bowel syndrome, post-traumatic stress disorder, and more. Recently, Yunus has suggested the term central sensitivity syndromes to describe FM and related conditions [18].

The concept of central sensitivity syndrome has been suggested to be based on mutual associations among the central sensitivity syndrome conditions as well as the evidence for central sensitization among several central sensitivity syndrome members. It was suggested that such evidence is weak or is not available in other members at this time, however, and therefore further studies are required [18]. The biology of central sensitivity syndrome was concluded to be based on neuroendocrine aberrations, including central sensitization, that interact with psychosocial factors to cause a number of symptoms [18]. Kanaan and colleagues have suggested that phenomenological commonalities support a close relationship between the FSS [19], although differences remain in other domains. It was concluded that whether the FSS may best be considered the same or different will depend on the pragmatics of diagnosis [19].

FSS may share pathogenetic mechanisms as well. Central sensitization that involves hyperexcitement of the central neurons through various synaptic and neurotransmitter/neurochemical activities has been demonstrated in several FSS. Most neuroimaging studies conducted have demonstrated differences within the central nervous system, whether at baseline or in response to stimulation in patients with various somatic syndromes [20].

Recent evidence suggests these syndromes may share heritable pathophysiological features and similar polymorphisms of genes in the serotoninergic, dopaminergic and 
catecholaminergic systems in FM and other FSS (discussed below in Genetics) [21]. Compared with controls, female patients with interstitial cystitis/painful bladder syndrome showed increased activation of a defensive emotional circuit in the context of a threat of abdominal pain [22]. It was suggested by the authors that since these circuits have an important role in central pain amplification related to affective and cognitive processes, the observed abnormality may be involved in the enhanced signals associated with interstitial cystitis/painful bladder syndrome [22]. Bradesi and colleagues demonstrated recently that stress-induced activation of spinal microglia has a key role in visceral hyperalgesia and associated spinal NK1R receptor upregulation [23]. Henningsen and colleagues provided an overview of current concepts underlying the management of FSS, of results of appropriate therapeutic trials in single syndromes and diagnostic analogues, and of practical steps for management [24]. It was concluded that nonpharmacologic treatments involving active participation of patients, such as exercise and psychotherapy, seem to be more effective than those that involve passive physical measures, including injections and operations.

Pharmacological agents with central nervous system action seem to be more consistently effective than drugs aiming at restoration of peripheral physiological dysfunction. Henningsen and colleagues suggested that a balance between biomedical approaches, organ-oriented approaches and cognitive interpersonal approaches is most appropriate [24].

\section{Fibromyalgia and autoimmune disorders}

$\mathrm{FM}$ is common in patients with autoimmune disease and may be the source of many of the symptoms and much of the disability in these patients $[25,26]$. Although FM is generally regarded as a noninflammatory and nonautoimmune disease, some patients have evidence of autoimmunity [27]. Although some FM patients display autoimmunity and FM is prevalent in autoimmune diseases, referring to $F M$ as an autoimmune disease is speculative at the present time. The association of FM and autoimmune disease, specifically systemic lupus erythematosus, may pose diagnostic dilemmas. Although FM does not correlate with systemic lupus erythematosus disease activity, the clinical features of FM in these patients may contribute to misinterpretation of lupus activity [27]. The pain associated with arthritis in these autoimmune diseases may act as a peripheral pain generator, triggering or enhancing widespread pain.

\section{Genetics}

Recent evidence suggests that genetic factors may play a role in the pathogenesis of FM $[4-6,21]$ (see Tables 1 and 2). Certain environmental factors (stressors) may trigger the development of FM in genetically predisposed individuals [11].

A number of studies published over recent years have documented increased prevalence of FM among family members of patients suffering from this syndrome [28-30].
Table 1

Genetic markers in fibromyalgia

\begin{tabular}{|c|c|}
\hline System & Genetic marker \\
\hline \multirow[t]{2}{*}{ Serotoninergic } & $\begin{array}{l}5-\mathrm{HT} 2 \mathrm{~A} \text { receptor polymorphism } \mathrm{T} / \mathrm{T} \\
\text { phenotype }\end{array}$ \\
\hline & SLC6A4 serotonin transporter \\
\hline Dopaminergic & $\begin{array}{l}\text { Dopamine } \mathrm{D}_{4} \text { receptor exon III repeat } \\
\text { polymorphism }\end{array}$ \\
\hline Catecholaminergic & $\begin{array}{l}\text { Catecholamine O-methyl transferase } \\
\text { polymorphism }\end{array}$ \\
\hline
\end{tabular}

Table 2

Future clinical implications of molecular genetic findings in fibromyalgia

Subgrouping of fibromyalgia patients

Pharmacologic treatment based on knowledge of patient's genotype

- Subjects with the short 5-HTTLPR allele may be more suitable candidates for antidepressant medication

- Subjects without the 7DRD4 allele may be candidates for dopaminergic medication

Buskila and colleagues found that $28 \%$ of offspring of $\mathrm{FM}$ patients fulfilled the 1990 ACR classification criteria for the diagnosis of FM [28]. The authors have further reported that the prevalence of $\mathrm{FM}$ among blood relatives of patients with FM was $26 \%$, and that the FM prevalence in male and female relatives was $14 \%$ and $41 \%$, respectively [29]. Arnold and colleagues reported that FM aggregates strongly in families: the odds ratio measuring the odds of $F M$ in a relative of a proband with FM versus the odds of FM in a relative of a proband with rheumatoid arthritis was 8.5 [30]. Research performed in recent years has demonstrated a role for polymorphisms of genes in the serotoninergic, dopaminergic and catecholaminergic systems in the etiology of FM [4-6,21]. Polymorphisms in the serotonin 5-HT2A receptor ( $T / T$ phenotype), in the serotonin transporter, in the dopamine 4 receptor and in the catecholamine O-methyltransferase enzyme have therefore been detected at higher frequencies in patients with FM [4-6,21].

Notably, these polymorphisms all affect the metabolism or transport of monoamines, compounds that have a critical role in both sensory processing and the human stress response [31]. These polymorphisms are not specific for FM and are associated with other FSS. The mode of inheritance of FM is unknown but it is most probably polygenic.

Future large, well-designed studies are needed to further clarify the role of genetic factors in FM. The knowledge of 
Table 3

\section{Triggers capable of precipitating fibromyalgia}

Physical trauma

Psychologic stress/distress (acute and/or chronic)

Infections

Peripheral pain syndromes (autoimmune diseases, osteoarthritis, complex regional pain syndrome)

these gene polymorphisms may help with better subgrouping of FM patients and in designing a more specific pharmacologic treatment approach.

\section{Triggers}

In addition to the genetic associations, various external stimuli such as infection, trauma and stress may contribute to development of the syndrome (see Table 3). Bennett and colleagues provided an Internet survey of 2,596 people with FM [32]. Approximately $21 \%$ of responders indicated that they could not identify any triggering events of their illness. Over $73 \%$ of those who indicated some triggering event made attributions to emotional trauma or chronic stress. The next most common attribution was acute illness (26.7\%), followed by physical stressors (surgery, motor vehicle collisions, and other injuries). Various infectious agents have been linked to the development of FM as well as to that of the closely related chronic fatigue syndrome.

Viral agents, including hepatitis $\mathrm{C}$ and HIV, have been associated with $\mathrm{FM}$ on epidemiological and clinical grounds [33,34]. In particular cases, such as Lyme disease and HIV, obvious overlap of clinical manifestations can be described; nonetheless, evidence of the utility of antibiotic or antiviral treatment in FM or chronic fatigue syndrome is lacking [35].

Various forms of physical trauma have been implicated as triggering events in the pathogenesis of FM. Increased rates of FM have been demonstrated among patients undergoing cervical trauma during motor vehicle accidents [36]. Most recently, Wynne-Jones and colleagues found a $7.8 \%$ frequency of widespread pain within 12 months among a cohort of patients who underwent a motor vehicle collision [37]. Emotional trauma and stress have also been implicated as triggers of FM. Post-traumatic stress disorder may precipitate the development of FM, and both conditions share similar pathogenic mechanisms [38].

\section{Pathogenesis of fibromyalgia}

Tremendous progress in the past decade has been made in our understanding of $\mathrm{FM}$, which is now recognized as one of many central pain syndromes [31]. Central sensitization is an emerging biopsychosocial concept currently considered to characterize a wide spectrum of interrelated FSS, which may subsequently be better defined as central sensitivity syndromes [18].

Central sensitization constitutes a condition of general overreactivity of the central nervous system to a wide spectrum of stimulation.

Various areas in the central nervous system are responsible for inhibiting ascending pain transmission within the spinal cord through the activity of inhibitory neurotransmitters, which include serotonin, norepinephrine, enkephalins, $\gamma$-amino butyric acid and adenosine. A decrease in this pain inhibitory loop is an important component of central sensitization syndrome [39]. Separate areas of the central nervous system, including the limbic system and the medial thalamic nuclei, are involved in the affective response of the central nervous system to pain [40].

The advent of imaging techniques has provided valuable insight into the biological meaning of central sensitization in FM. Using functional magnetic resonance imaging, Gracely and colleagues were able to demonstrate that conditions resulting in comparable subjective sensation of pain also resulted in activation patterns that were similar in FM patients and control individuals; on the other hand, similar levels of pressure (which invoke higher levels of pain among FM patients relative to control individuals) resulted in activation of different areas and caused greater effects in patients [41]. Cook and colleagues similarly showed that, in response to painful stimuli, FM patients had greater activity in the contralateral insular cortex than healthy control individuals [42], as demonstrated by functional magnetic resonance imaging. Pain catastrophizing was significantly associated with increased activity in some brain areas related to anticipation of pain (medial frontal cortex, cerebellum), attention to pain (dorsal anterior cingulate cortex, dorsolateral prefrontal cortex) and emotional aspects of pain [43]. These results suggested that catastrophizing influences pain perception by altering attention and anticipation, and by heightening emotional responses to pain [43]. A recent study by Harris and colleagues used $\mu$-opioid receptor positron emission tomography in FM patients and in matched healthy control individuals [44]. The study demonstrated that FM patients display reduced $\mu$-opioid receptor within several regions that play an important role in pain regulation, such as the nucleus accumbens, the dorsal cingulate and the amygdala. These results indicate altered endogenous opioid analgesic activity in FM and explain why exogenous opiates appear to have reduced efficacy in this population.

Changes in glutamate levels within the insula were demonstrated recently to be associated with changes in multiple pain domains in patients with FM [45]. It was suggested that proton magnetic resonance spectroscopy data may serve as a useful biomarker and surrogate endpoint for clinical trials of FM. Functional brain imaging techniques have thus supplied 
Table 4

Drugs approved by the Food and Drugs Administration for treatment of fibromyalgia

\begin{tabular}{lll}
\hline Drug & Class & Mechanism \\
\hline Duloxetine & Antidepressant & Balanced norepinephrine and serotonin reuptake inhibition \\
Milnacipran & Antidepressant & Balanced norepinephrine and serotonin reuptake inhibition \\
Pregabalin & Anticonvulsant & $\alpha_{2} \delta$ ligand; affects calcium influx and release of excitatory amino acids and neuropeptides \\
\hline
\end{tabular}

FM researchers with a long-awaited tool for objective evaluation of pain. This tool enables further evaluation of various factors capable of influencing the functioning of the nervous system as well as response to pharmacological interventions. Perturbations in the hypothalamic-pituitaryadrenal axis have been demonstrated in FM patients [46]. Similarly, alterations in the functioning of the autonomic nervous system have frequently been described in FM [47]. Autonomic dysfunction is inherent to FM [48]. Sympathetic hyperactivity has been described by diverse groups of investigators in FM [49]. Cohen and colleagues reported on abnormal sympathovagal balance in men with sympathetic hyperactivity and concomitantly reduced parasympathetic activity [50]. The basal autonomic state of patients with FM was characterized by increased sympathetic and decreased parasympathetic tones in women with FM [51]. It was suggested that autonomic dysregulation may have implications regarding the symptomatology, physical and psychological aspects of health status [51].

Solano and colleagues reported that patients with FM have multiple nonpain symptoms related to different expressions of autonomic dysfunction, and that there was a correlation between the Fibromyalgia Impact Questionnaire and an autonomic dysfunction questionnaire [48].

Nonrestorative sleep is common in FM. About $75 \%$ of patients report sleep disturbances, including early middle or late insomnia, hypersomnia and frequent awakening. Moldofsky and colleagues were the first to demonstrate that the disruption of stage 4 nonrapid eye movement or deep sleep in normal healthy people by noise stimuli resulted in complaints of unrefreshing sleep, variable aching and fatigue [52]. FM patients reported more insomnia-related symptoms than either rheumatoid arthritis patients or a population sample [53]. The higher prevalence of insomnia-related symptoms among FM patients was not explained by depression or pain [53].

Finally, there is a continuous effort to identify objective measurable biomarkers in FM patients that may identify susceptible individuals, may facilitate diagnosis or that parallel activity of the disease [54]. Dadabhoy and colleagues provided a systematic literature review assessing highly investigated, objective measures used in FM studies. The authors concluded that to date only experimental pain testing has been shown to coincide with improvements in clinical status in a longitudinal study [54].

Concerted efforts to systematically evaluate additional objective measures in research trials have been suggested vital for ongoing progress in outcome research and translation into clinical practice [54].

\section{Management of fibromyalgia}

As FM is a complex syndrome associated with a wide range of symptoms, treatment should be tailored to the individual, dealing with their particular needs and targeting their most distressing symptoms. The aim of treating FM is to decrease pain and to increase function by means of a multimodal therapeutic strategy, which in most cases includes pharmacologic interventions [55,56]. Recently, the Food and Drugs Administration approved three drugs for the treatment of FM: pregabalin, duloxetine, and milnacipran (see Table 4). This fact may herald a new era for the development of medication with higher specificity and efficacy for this condition.

Pregabalin is an $\alpha_{2} \delta$ ligand that reduces calcium influx at nerve terminals and therefore reduces the release of several neurochemicals, including glutamate, noradrenalin and substance $P$ [57]. Crofford and colleagues [58] compared the effects of pregabalin (150, 300 and $450 \mathrm{mg} /$ day) on pain, sleep, fatigue and health-related quality of life in 529 FM patients, and found that it was superior to placebo in reducing the scores for pain, the short-form McGill Pain Questionnaire, the sleep index, fatigue, patient and clinician global impression of change, and four of the eight short-form SF-36 domains. Arnold and colleagues reported that anxiety symptoms were more common than depressive symptoms in their cohort of FM patients and that the pain treatment effect of pregabalin did not depend on baseline anxiety or depressive symptoms [59], suggesting that pregabalin improves pain in patients with or without these symptoms. Much of the pain reduction appeared to be independent of improvements in anxiety or mood symptoms [59].

Mease and colleagues evaluated the efficacy and safety of pregabalin for symptomatic relief of pain associated with FM and for management of FM [60]. This multicenter, doubleblind, placebo-controlled trail randomly assigned 748 
patients with FM to receive placebo or pregabalin 300,450 or $600 \mathrm{mg} /$ day for 13 weeks. Patients in all pregabalin groups showed statistically significant improvement in the endpoint mean pain score and in patient global impression of change response compared with placebo. Improvements in the Fibromyalgia Impact Questionnaire total score for the pregabalin groups were numerically greater but not significantly greater than those for the placebo group. The authors concluded that pregabalin provides clinically meaningful benefit to patients with FM.

In another study Mease and colleagues evaluated the safely and efficacy of milnacipran, a dual norepinephrine and serotonin reuptake inhibitor in the treatment of FM, in a 27week randomized, double-blind, multicenter study [61]. They compared milnacipran 100 and $200 \mathrm{mg} /$ day with placebo in the treatment of 888 patients with FM. At the primary endpoint, after 3 months of stable dose treatment, a significantly higher percentage of milnacipran-treated patients met the criteria than FM responders versus placebo. A significantly higher percentage of patients treated with milnacipran $200 \mathrm{mg} /$ day also met the criteria as FM pain responders versus placebo. At 15 weeks, milnacipran $200 \mathrm{mg} /$ day led to significant improvements over placebo in pain, patient global impression of change, fatigue, cognition and multiple shortform SF-36 domains. Milnacipran was safe and well tolerated by the majority of patients during 27 weeks of treatment [61]. In a different study, both doses of milnacipran (100 and $200 \mathrm{mg} /$ day) were associated with significant improvements in pain and other symptoms [62].

Duloxetine is a norepinephrine and serotonin reuptake inhibitor. Two 12-week randomized, double-blind, placebocontrolled trials have evaluated duloxetine in patients with FM $[63,64]$. Compared with patients on placebo, FM patients treated with duloxetine $60 \mathrm{mg}$ once daily or with duloxetine $60 \mathrm{mg}$ twice daily had significantly greater improvement in remaining Brief Pain Inventory pain severity and interference scores, Fibromyalgia Impact Questionnaire scores, Clinical Global Impression of Severity scores, Patient Global Impression of Improvement scores, and several quality of life measures. The authors concluded that both duloxetine $60 \mathrm{mg}$ once daily and duloxetine $60 \mathrm{mg}$ twice daily were effective and safe in the treatment of FM in female patients with or without major depressive disorder [63]. In the other randomized controlled 12-week trial, duloxetine was an effective and safe treatment for many of the symptoms associated with FM in subjects with or without major depressive disorder, particularly for women who had significant improvement across most outcome measures [64].

Hauser and colleagues provided a meta-analysis of clinical trials (randomized controlled trials) assessing the efficacy of multicomponent treatment in FM [65]. There was strong evidence for the efficacy of multicomponent therapy to reduce some key symptoms of FM, such as pain, fatigue and depressed mood, and to improve self-efficacy and physical fitness post treatment. There was also strong evidence that the positive effects of multicomponent therapy on the key symptoms of FM decline with time [65]. A systematic review of papers on antidepressants in rheumatological conditions was performed [66]. The strongest evidence on an analgesic effect of antidepressants has been obtained for FM.

Analgesic effects of antidepressants were independent of their antidepressant effects. Tricyclic antidepressants, even at low doses, had analgesic effects equivalent to those of serotonin and noradrenalin reuptake inhibitors, but were less well tolerated. Selective serotonin reuptake inhibitors had modest analgesic effects, but higher doses were required to achieve analgesia [66].

A systematic review on the effectiveness of treatment with antidepressants in fibromyalgia syndrome found that amitriptyline 25 to $50 \mathrm{mg} /$ day reduces pain, fatigue and depressiveness in patients with FM, and improves sleep and quality of life [67]. It was concluded that most selective serotonin reuptake inhibitors and the serotonin and noradrenalin reuptake inhibitors duloxetine and milnacipran are probably also effective. The review suggested that short-term treatment of patients with FM using amitriptyline or another of the antidepressants that were effective in randomized controlled trials can be recommended. It was stressed that data on long-term efficacy are lacking [67]. A EULAR task force developed management recommendations for FM based on a systematic review [68]. The nine recommendations included eight management categories; three of which had strong evidence from the current literature, and three were based on expert opinion [68]. Clinical studies demonstrate the effectiveness of the $\alpha_{2} \delta$ ligands (gabapentine and pregabalin) and the norepinephrine/serotonin reuptake inhibitors (duloxetine and milnacipran) in FM [69]. Exercise is a crucial part of treatment for FM patients.

A comprehensive review of 46 exercise treatment studies in FM reported that the strongest evidence was in support of aerobic exercise [70]. In general, the greatest effect and lowest attrition occurred in exercise programs that were of lower intensity than those of higher intensity [70]. The combination of nonpharmacological treatments such as exercise programs and psychological support together with analgesics and off-label use of tricyclic medications, sedative hypnotics and reuptake inhibitors have all led to limited success; the recent introduction of pregabalin, an $\alpha_{2} \delta$ ligand, and the serotonin and noradrenalin reuptake inhibitors duloxetine and milnacipran is a promising development in the field of FM [71]. The current research being carried out on novel sedative hypnotics, antiepileptic medications, various reuptake inhibitors, growth hormone agonists, canabinoid agonists and 5-HT3 antagonists offers hope for future improvement in our therapeutic options for dealing with FM. 


\section{The Scientific Basis of Rheumatology: A Decade of Progress}

This article is part of a special collection of reviews, The Scientific Basis of Rheumatology: A Decade of Progress, published to mark Arthritis Research \& Therapy's 10th anniversary.

Other articles in this series can be found at: http://arthritis-research.com/sbr

\section{Conclusion}

Major progress has been reached in our understanding of FM in the past decade. High prevalence marks the syndrome that is considered to reflect altered central pain processing. Genetic and environmental factors may play a role in the etiopathology of FM and other related syndromes. FM requires a multimodal management program including pharmacologic and nonpharmacologic modalities.

New medications have been developed and clinical studies demonstrate the effectiveness of the $\alpha_{2} \delta$ ligands (pregabalin) and the serotonin and noradrenalin reuptake inhibitors (duloxetine and milnacipran). As our understanding of the biological basis in general - and the genetic underpinning, in particular - of FM increases, we hope to gain a better understanding of the true nature of the disorder, to attain more rational therapeutic modalities, and to help patients.

\section{Competing interests}

The author declares that he is a consultant and on the speaker bureaus for Pfizer and Pierre Fabre Medicament.

\section{References}

1. Wolfe F, Smythe HA, Yunus MB, Bennett RM, Bombardier C Goldenberg DL, Tugwell P, Campbell SM, Abeles M, Clark P, Fam $A D$, Farber SJ, Flechtner JJ, Franklin CM, Gatter RA, Hamaty D, Lessard J, Lichtbroun AS, Masi AT, McCain GA, Reynolds WJ. Romano TJ, Russell IJ, Sheon RP: The American College of Rheumatology criteria for the classification of fibromyalgia: report of the multicenter criteria committee. Arthritis Rheum 1990, 33:160-172.

2. Inanici F, Yunus MB: History of fibromyalgia: past to present. Curr Pain Headache Rep 2004, 8:369-378.

3. Ablin J, Neumann L, Buskila D: Pathogenesis of fibromyalgia - a review. Joint Bone Spine 2008, 75:273-279.

4. Buskila D: Genetics of chronic pain states. Best Pract Res Clin Rheumatol 2007, 21:535-547.

5. Buskila $D$, Sarzi-Puttini $P$, Ablin $J N$ : The genetics of fibromyalgia syndrome. Pharmacogenomics 2007, 8:67-74.

6. Ablin JN, Cohen H, Buskila D: Mechanisms of disease: genetics of fibromyalgia. Nat Clin Pract Rheumato/ 2006, 2:671-678.

7. Dadabhoy D, Crofford LJ, Spaeth M, Russell IJ, Clauw DJ: Biology and therapy of fibromyalgia. Evidence-based biomarkers for fibromyalgia syndrome. Arthritis Res Ther 2008, 10:211.

8. Crofford $L$, Clauw DJ: Fibromyalgia: where are we a decade after the American College of Rheumatology classification criteria were developed? Arthritis Rheum 2002, 46:1136-1138.

9. Harth $M$, Nielson WR: The fibromyalgia tender points: use them or lose them? A brief review of the controversy. $J$ Rheumatol 2007, 34:914-922.

10. Wolfe F: The relation between tender points and fibromyalgia symptom variables: evidence that fibromyalgia is not a discrete disorder in the clinic. Ann Rheum Dis 1997, 56:268-271.

11. Clauw DJ, Crofford LJ: Chronic widespread pain and fibromyalgia: what we know, and what we need to know. Best Pract Res Clin Rheumatol 2003, 17:685-701.

12. Wolfe F: Pain extent and diagnosis: development and validation of the regional pain scale in 12,799 patients with rheumatic disease. J Rheumatol 2003, 30:369-378.

13. Turk DC, Okifuji A, Sinclair JD, Starz TW: Pain, disability and physical functioning in subgroups of patients with fibromyalgia. J Rheumatol 1996, 23:1255-1262.

14. Turk DC, Okifuji A, Sinclair JD, Starz TW: Differential responses by psychosocial subgroups of fibromyalgia syndrome patients to an interdisciplinary treatment. Arthritis Care Res 1998, 11:397-404.

15. Thieme K, Spies C, Sinha P, Turk DC, Flor H: Predictors of pain behaviors in fibromyalgia syndrome. Arthritis Rheum 2005, 53: 343-350.

16. Giesecke T, Williams DA, Harris RE, Cupps TR, Tian X, Tian TX, Gracely $\mathrm{RH}$, Clauw DJ: Sub grouping of fibromyalgia patients on the basis of pressure-pain thresholds and psychological factors. Arthritis Rheum 2003, 48:2916-2922.

17. Masuko K, Nakamura H: Functional somatic syndrome: how it could be relevant to rheumatologists. Mod Rheumatol 2007, 17:179-184.

18. Yunus MB: Fibromyalgia and overlapping disorders: the unifying concept of central sensitivity syndromes. Semin Arthritis Rheum 2007, 36:339-356.

19. Kanaan RA, Lepine JP, Wessely SC: The association or otherwise of the functional somatic syndromes. Psychosom Med 2007, 69:855-859.

20. Wood PB: Neuroimaging in functional somatic syndromes. Int Rev Neurobiol 2005, 67:119-163.

21. Buskila D, Sarzi-Puttini P: Biology and therapy of fibromyalgia. Genetic aspects of fibromyalgia syndrome. Arthritis Res Ther 2006, 8:218.

22. Twiss $C$, Kilpatrick L, Craske M, Buffington CA, Ornitz E, Rodriguez LV, Mayer EA, Naliboff BD: Increased startle responses in interstitial cystitis: evidence for central hype responsiveness to visceral related threat. J Uro/ 2009, 181:2127-2133.

23. Bradesi S, Svensson Cl, Steinauer J, Pothoulakis C, Yaksh TL, Mayer EA: Role of spinal microglia in visceral hyperalgesia and NK $1 R$ up-regulation in a rat model of chronic stress. Gastroenterology 2009, 136:1339-1348.

24. Henningsen P, Zipfel S, Herzog W: Management of functional somatic syndromes. Lancet 2007, 369:946-955.

25. Neumann L, Buskila D: Epidemiology of fibromyalgia. Curr Pain Headach Rep 2003, 7:362-363.

26. Buskila D, Press J, Abu-shakra M: Fibromyalgia in systemic lupus erythematosus: prevalence and clinical implications. Clin Rev Allergy Immunol 2003, 25:25-28.

27. Buskila D, Sarzi-Puttini P: Fibromyalgia and autoimmune diseases: the pain behind autoimmunity. Isr Med Assoc J 2008 10:77-78.

28. Buskila D, Neumann L, Hazanov I, Carmi R: Familial aggregation in the fibromyalgia syndrome. Semin Arthritis Rheum 1996, 26: 605-611.

29. Buskila D, Neumann L: Fibromyalgia syndrome (FM) and nonarticular tenderness in relatives of patients with FM. $J$ Rheumatol 1997, 24:941-944.

30. Arnold LM, Hudson J, Hess EV, Ware AE, Fritz DA, Auchenbach MB, Starck LO, Keck PE, Jr: Family study of fibromyalgia. Arthritis Rheum 2004, 50:944-952.

31. Dadabhoy D, Clauw DJ: Therapy insight: fibromyalgia a different type of pain needing a different type of treatment. Nat Clin Pract Rheumatol 2006, 2:364-372.

32. Bennett RM, Jones J, Turk DC, Russell IJ, Matallana L: An internet survey of 2,596 people with fibromyalgia. BMC Musculoskelet Disord 2007, 8:27.

33. Buskila D, Shnaider A, Neumann L, Zilberman D, Hilzenrat N, Sikuler E: Fibromyalgia in hepatitis $\mathrm{C}$ virus infection. Another 
infectious disease relationship. Arch Intern Med 1997, 157: 2497-2500.

34. Buskila D, Gladman DD, Langevitz P, Urowitz S, Smythe HA: Fibromyalgia in human immunodeficiency virus infection. J Rheumatol 1990, 17:1202-1206.

35. Ablin JN, Shoenfeld Y, Buskila D: Fibromyalgia, infection and vaccination: two more parts in the etiological puzzle. J Autoimmun 2006, 27:145-152.

36. Buskila D, Neumann L, Vaisberg G, Alkalay D, Wolfe F: Increased rates of fibromyalgia following cervical spine injury. A controlled study of 161 cases of traumatic injury. Arthritis Rheum 1997, 40:446-452

37. Wynne-Jones G, Jones GT, Wiles NJ, Silman AJ, Macfarlane GJ: Predicting new onset of widespread pain following a motor vehicle collision. J Rheumatol 2006, 33:968-974.

38. Buskila D, Cohen H: Comorbidity of fibromyalgia and psychiatric disorders. Curr Pain Headache Rep 2007, 11:333-338.

39. Millan MJ: Descending control of pain. Prog Neurobiol 2002, 66:355-474.

40. Price DD: Psychological and neural mechanisms of the affective dimension of pain. Science 2000, 288:1769-1772.

41. Gracely RH, Petzke F, Wolf JM, Clauw DJ: Functional magnetic resonance imaging evidence of augmented pain processing in fibromyalgia. Arthritis Rheum 2002, 46:1333-1343.

42. Cook DB, Lange G, Ciccone DS, Liu WC, Steffener J, Natelson $\mathrm{BH}$ : Functional imaging of pain in patients with primary fibromyalgia. J Rheumatol 2004, 31:364-378.

43. Gracely RH, Geisser ME, Giesecke T, Grant MA, Petzke F, Williams DA, Clauw DJ: Pain catastrophizing and neural responses to pain among persons with fibromyalgia. Brain 2004, 127:835-843.

44. Harris RE, Clauw DJ, Scott DJ, Mclean SA, Gracely RH, Zubieta JK: Decreased central mu-opioid receptor availability in fibromyalgia. J Neurosci 2007, 27:10,000-10,006.

45. Harris RE, Sundgren PC, Pang Y, Hsu M, Petrou M, Kim SH, McLean SA, Gracely RH, Clauw DJ: Dynamic levels of glutamate within the insula are associated with improvements in multiple pain domains in fibromyalgia. Arthritis Rheum 2008, 58:903-907.

46. Crofford LJ, Pillemer SR, Kalogeras KT, Cash JM, Michelson D, King MA, Sternberg EM, Gold PW, Chrousos GP, Wilder RL: Hypothalamic-pituitary-adrenal axis perturbations in patients with fibromyalgia. Arthritis Rheum 1994, 37:1583-1592.

47. Cohen $H$, Neumann L, Kotler M, Buskila D: Autonomic nervous system derangement in fibromyalgia syndrome and related disorders. Isr Med Assoc J 2001, 3:755-760.

48. Solano C, Martinez A, Becerril L, Vargas A, Figueroa J, Navarro C, Ramos-Remus C, Martinez-Lavin M: Autonomic dysfunction in fibromyalgia assessed by the composite autonomic symptoms scale (COMPASS). J Clin Rheumatol 2009, 15:172-176.

49. Martinez-Lavin M: Biology and therapy of fibromyalgia. Stress, the stress response system, and fibromyalgia. Arthritis Res Ther 2007, 9:216.

50. Cohen H, Neumann L, Alhosshle A, Kotler M, Abu-Shakra M, Buskila D: Abnormal sympathovagal balance in men with fibromyalgia. J Rheumato/ 2001, 28:581-589.

51. Cohen H, Neumann L, Shore M, Amir M, Cassuto Y, Buskila D: Autonomic dysfunction in patients with fibromyalgia: application of power spectral analysis of heart rate variability. Semin Arthritis Rheum 2000, 29:217-227.

52. Moldofsky $H$, Scarisbrick $P$, England $R$, Smythe $H$ : Musculoskeletal symptoms and non-REM sleep disturbance in patients with 'fibrositis syndrome' and healthy subjects. Psychosom Med 1975, 37:341-351.

53. Belt NK, Kronholm E, Kauppi MJ: Sleep problems in fibromyalgia and rheumatoid arthritis compared with the general population. Clin Exp Rheumatol 2009, 27:35-41.

54. Dadabhoy D, Crofford LJ, Spaeth M, Russell IJ, Clauw DJ: Biology and therapy of fibromyalgia. Evidence-based biomarkers for fibromyalgia syndrome. Arthritis Res Ther 2008, 10:211.

55. Burckhardt CS: Multidisciplinary approaches for management of fibromyalgia. Curr Pharm Design 2006, 12:59-66.

56. Sarzi-Puttini $P$, Buskila D, Carrabba M, Doria A, Atzeni F: Treatment strategy in fibromyalgia syndrome: where are we now? Semin Arthritis Rheum 2008, 37:353-365.

57. Fink K, Dooley DJ, Meder WP, Suman-Chauhan N, Duffy S, Clus- mann $\mathrm{H}$ : Inhibition of neuronal $\mathrm{Ca}^{2+}$ influx by gabapentin and pregabalin in the human neocortex. Neuropharmacology 2002 42:229-236.

58. Crofford L, Rowbotham MC, Mease PJ, Russell IJ, Dworkin RH, Corbin AE, Young JP Jr, LaMoreaux LK, Martin SA, Sharma U; Pregabalin 1008-105 Study Group: Pregabalin for the treatment of fibromyalgia syndrome: results of a randomized, double blind placebo-controlled trial. Arthritis Rheum 2005, 52:1264-1273.

59. Arnold LM, Crofford LJ, Martin SA, Young JP, Sharma U: The effect of anxiety and depression on improvements in pain in a randomized controlled trial of pregabalin for treatment of fibromyalgia. Pain Med 2007, 8:633-639.

60. Mease PJ, Russell IJ, Arnold LM, Florian H, Young JP Jr, Martin SA, Sharma M: A randomized, double blind placebo controlled, phase III trial of pregabalin in the treatment of patients with fibromyalgia. J Rheumatol 2008, 35:502-514.

61. Mease PJ, Clauw DJ, Gendreau RM, Rao SG, Kranzler J, Chen W, Palmer RH: The efficacy and safety of milnacipran for treatment of fibromyalgia. A randomized, double blind, placebo controlled trial. J Rheumatol 2009, 36:398-409.

62. Clauw DJ, Mease P, Palmer RH, Genderau RM, Wang Y: Milnacipran for the treatment of fibromyalgia in adults: a 15week multicenter, randomized, double blind placebo controlled, multiple dose clinical trial. Clin Ther 2008, 30: 1988-2004.

63. Arnold LM, Rosen A, Pritchett YL, D' Souza DN, Goldstein DJ, Ivengar S, Wernicke JF: A randomized, double blind placebo controlled trial of duloxetine in the treatment of women with fibromyalgia with or without major depressive disorder. Pain 2005, 119:5-15.

64. Arnold LM, Lu Y, Crofford LJ, Wohlreich M, Detke MJ, lyengar S, Goldstien DJ: A double blind multicenter trial comparing duloxetine with placebo in the treatment of fibromyalgia patients with or without major depressive disorder. Arthritis Rheum 2004, 50:2974-2984.

65. Hauser W, Bernardy K, Arnold B, Offenbacher M, Schiltenwolf M: Efficacy of multicomponent treatment in fibromyalgia syndrome: a meta analysis of randomized controlled clinical trials. Arthritis Rheum 2009, 61:216-224.

66. Perrot $S$, Jovier RM, Marty $M$, Jeunne $C$, Laroche $F$, and the Cercle d'Etude de la Douleur en Rheumatologie France, French Rheumatological Society, Pain Study Section: Is there any evidence to support the use of anti depressants in painful rheumatological conditions? Systematic review of pharmacological and clinical studies. Rheumatology 2008, 7:1117-1123.

67. Uceyler N, Hauser W, Sommer C: A systematic review on the effectiveness of treatment with antidepressants in fibromyalgia syndrome. Arthritis Rheum 2008, 59:1279-1298.

68. Carville SF, Arendt-Nielsen S, Bliddal H, Blotman F, Branco JC, Buskila D, Da Silva JA, Danneskiold-Samsoe B, Dincer F, Henriksson C, Henriksson KG, Kosek E, Longley K, McCarthy GM, Perrot S, Puszczewicz M, Sarzi-Puttini P, Silman A, Spath M, Choy EH; EULAR: EULAR evidence-based recommendations for the management of fibromyalgia syndrome. Ann Rheum Dis 2008, 67:1536-1541.

69. Crofford LJ: Pain managemnent in fibromyalgia. Curr Opin Rheumato/ 2008, 20:246-250.

70. Jones KD, Adams D, Winters-Stone K, Burckhardt CS: A Comprehensive review of 46 exercise treatment studies in fibromyalgia (1988-2005). Health Qual Life Outcomes 2006, 4: 67.

71. Ablin JN, Buskila D: Emerging therapies for fibromyalgia. Expert Opin Emerging Drugs 2008, 13:53-62. 